\title{
ESCREVER É RESISTIR. PRÁTICAS DE RESISTÊNCIA NOS PAPÉIS DA PRISÃO DE LUANDINO VIEIRA
}

\author{
Elisa Scaraggi ${ }^{1}$
}

Resumo: Neste trabalho, seguindo as linhas mestras definidas por pesquisas históricas (Buntman 2003; McEvoy 2015), exploro o conceito de resistência no contexto da prisão, destacando como as condições materiais são essenciais para que haja resistência, e para determinar a forma que esta assume. À luz destas considerações, procedo à análise de alguns aspetos da obra Papéis da Prisão (2015), de José Luandino Vieira. Feito preso político durante a luta pela independência de Angola, José Luandino Vieira escreveu a maior parte de sua literatura de ficção durante a reclusão, além de dezessete cadernos de apontamentos que foram recentemente publicados com o título Papéis da Prisão. O meu objetivo não é só analisar os Papéis como exemplo de resistência em si, mas também observar as diferentes práticas de resistência que a obra descreve.

Palavras-chave: José Luandino Vieira; Papéis da Prisão; práticas de resistência.

Abstract: Following the guidelines defined by the historical research on prisoners resistance (Buntman 2003; McEvoy 2015), in this work I explore the concept of resistance in the carceral context, emphasizing how material conditions are crucial for resistance to take place, and to determine how it is shaped. Starting from these considerations, I analyse some aspects of Papéis da Prisão (2015), by José Luandino Vieira. José Luandino Vieira was a political prisoner during the struggle for independence in Angola, and it was in prison that he wrote great part of his short stories and novels, in addition to the seventeen notebooks that have been recently published under the title Papéis da Prisão. My aim is not only to analyse the Papéis as an example of resistance in itself, but also to observe the different practice of resistance that the book describes.

Keywords: José Luandino Vieira; Papéis da Prisão; practices of resistance.

1 Aluna do programa de doutoramento FCT PhDComp, do Centro de Estudos Comparatistas da Faculdade de Letras da Universidade de Lisboa. Email: elisascaraggi@campus.ul.pt 
O conceito de escrita como forma de resistência tem tido grande difusão nos estudos literários, e em particular naqueles sobre a literatura produzida em contextos autoritários. Como já apontava Alfredo Bosi (2002), o conceito de resistência é polissêmico, e pode remeter tanto ao nível textual quanto ao nível contextual de uma obra. No caso de obras escritas na prisão, é importante partir das condições materiais do lugar de escrita para entender em que sentido elas se constituem como exemplos de resistência.

No ensaio "Narrativa e resistência", Bosi distingue entre resistência como tema da narrativa e resistência como forma imanente da escrita. Enquanto a primeira estaria ligada a obras que surgem de uma visão politicamente engajada, a segunda faz referência a obras dotadas de "uma tensão interna que as faz resistentes, enquanto escrita, e não só, ou não principalmente, enquanto tema. Quem diz escrita fala em categorias formadoras do texto narrativo, como o ponto de vista e a estilização da linguagem (Bosi 129 ,2002)”. A essas categorias, é preciso acrescentar outra complementar, que se revela no caso de obras escritas no cárcere: a resistência como condição histórica e material do texto.

Neste trabalho gostaria de me focar na dimensão histórica da escrita como forma de resistência trazendo exemplos da obra Papéis da Prisão (2015), de Luandino Vieira, uma edição filológica dos 17 cadernos de apontamentos que Luandino escreveu na prisão. Durante o tempo da sua reclusão, além dos cadernos que compõem os Papéis, Luandino escreveu a maior parte das suas obras de ficção. Analisando alguns aspetos dos Papéis da Prisão, o objetivo é, através do exemplo particular de Luandino Vieira, trazer luz sobre o conceito de resistência.

No seu ensaio sobre o nascimento da prisão, Michel Foucault mostra que a introdução do encarceramento como principal forma de punição tem sido essencial para promover os interesses das elites em detrimento das classes menos favorecidas (Foucault 276 ,1995). Além disso, seja em democracias, seja em regimes autoritários, a prisão tem sido um meio poderoso nas mãos dos governantes para afastar da esfera pública os grupos políticos dissidentes. $\mathrm{O}$ fato do regime colonialista português em Angola ter tido um cunho fascista tão evidente, só contribuiu a agravar as condições da repressão. Nesse contexto, muitas vezes as prisões eram arbitrárias e a acusação de ser terrorista e de praticar atividades subversivas contra a segurança de estado pairava sobre todos aqueles que ousavam, mesmo que pacificamente, se opor ao regime ou simplesmente expressar o desejo de mais autonomia e liberdade.

Acusado pelo regime salazarista de tentar “separar a Mãe-Pátria ou entregar a país estrangeiro todo ou parte do território português (Ribeiro \& Vecchi 17 ,2015)", Luandino Vieira conheceu prisões em vários pontos desse território. Preso em Lisboa em 20 de outubro de 1961, o escritor ficou alguns dias na prisão do Aljube antes de ser transferido para Luanda, onde ficaria até 1964, passando pelo Pavilhão Prisional da PIDE, pela Cadeia do Comando da Polícia de Segurança Pública e pela Cadeia Comarcã de Luanda. Em 1964 
foi transferido para o Campo de Trabalho de Chão Bom (Tarrafal), em Cabo Verde, onde ficaria até $1972^{2}$.

Apesar de ser muitas vezes considerada uma instituição secundária, a prisão não se situa às margens das sociedades modernas, mas é, ao contrário, parte integrante delas. Por isso, as prisões reproduzem, em parte, as caraterísticas da sociedade que as constrói. Nas prisões coloniais de Luanda vigoram as mesmas dinâmicas do sistema colonial, com toda a sua violência física e simbólica e com todos os seus preconceitos raciais, que persistiam apesar das mudanças operadas por lei ${ }^{3}$.

Ao mesmo tempo, porém, as prisões eram também “um observatório excepcional sobre a nação angolana” (Ribeiro \& Vecchi 17 ,2015), um espaço no qual pessoas de lugares e classes muito diferentes podiam entrar em contato e, eventualmente, se deixar contagiar pelo ideal da independência. À diferença do Tarrafal que, reaberto ${ }^{4}$ especificamente para receber presos políticos oriundos das então chamadas províncias ultramarinas, contava com uma população prisional mais homogênea, as prisões de Luanda juntavam presos políticos e presos comuns ${ }^{5}$. Essa caraterística influiu notavelmente na sociabilidade entre os reclusos e inclusive nas estratégias das quais eles se utilizaram para resistir à repressão.

Como salienta Mónica Silva, "na história do movimento de libertação angolano, não se pode exagerar a importância das prisões de Luanda (Silva 76,2016$)^{6 ”}$.

De fato, o acontecimento que desencadearia a guerra de independência foi o assalto às cadeias de Luanda no dia 4 de fevereiro de 1961, tentativa falida de libertar os presos políticos detidos na Casa de Reclusão Militar, na Prisão de São Paulo e noutros centros de detenção. $\mathrm{O}$ assalto espalhou o terror entre os colonos brancos ${ }^{7}$ e pegou as autoridades de surpresa.

\footnotetext{
2 Para mais informações, é possível consultar a cronologia comentada incluída no volume Papéis da Prisão (Vieira 2015, 1009-1023).

3 Frente à pressão internacional para descolonizar seus territórios africanos, o regime português tinha operado uma série de mudanças, como a abolição do Estatuto do Indígena, que separava a população em duas categorias: civilizados (brancos) e indígenas (negros e mestiços). Tratava-se, porém, de mudanças "para inglês ver", que não alteraram as dinâmicas discriminatórias da sociedade colonial. Como explica a historiadora Maria da Conceição Neto, "o abismo entre o discurso da igualdade racial e a realidade social nas colónias continuava a ser muito grande (Neto 1997, p.349)".

4 A partir de 1936, o campo funcionou como colônia penal para dissidentes portugueses do regime salazarista. Fechado em 1954, foi reaberto anos depois para deter os militantes nacionalistas africanos. Nesta segunda fase, o campo funcionou de 1962 a 1974.

5 Quando falo de presos políticos em relação à situação em Angola entre o final dos anos 1950 e meados dos 1970, me refiro a pessoas que foram presas por pertencerem a movimentos nacionalistas e anticoloniais. Este esclarecimento pode parecer inútil, mas o contexto histórico mostra que é necessário. De fato, depois dos acontecimentos de 4 de fevereiro 1961, a PIDE começou a prender arbitrariamente a população dos musseques e das zonas rurais, muitas vezes com a acusação de terrorismo. A entrada do dia 2/11/1962 dos cadernos de Luandino fornece uma amostra da situação: "Entrou uma grande leva de presos, vindos de Beça Monteiro. Alguns a K. viu-os eram aqueles velhotes todos. São só velhos, mulheres e crianças! (Os novos não os apanham e se apanham, matam.) Em cada grupo para identificação só um geralmente sabe (!) português e é intérprete. Os outros não sabem (!). Ler e escrever, ninguém! O Waldemar pergunta pela profissão e dão a resposta: «trabalhar com a catana». Talvez escreva «trabalhador agrícola», talvez escreva «terrorista». Mas o que escreve, que eu vi, é: «motivo da prisão: atividades subversivas contra a segurança exterior do Estado»! (Vieira $2015,51)$ ".

6 Não havendo indicação em contrário, todas as traduções são de minha autoria.

7 As verdadeiras vítimas, porém, foram os moradores pretos e pardos dos musseques, como explica Marcum: "A vingança dos portugueses foi terrível. A polícia ajudou milícias civis a organizar massacres noturnos nos musseques. Os brancos arrastavam os africanos das suas miseras barracas, disparavam-lhes e deixavam os corpos na rua. Um missionário metodista que se encontrava em Luanda disse que sabia por certo da morte de quase trezentas pessoas. Desconhecem-se as dimensões reais do massacre (Marcum 1969, I:129)".
} 
Contudo, já a partir da década anterior, os portugueses estavam se preparando para uma potencial revolta; por isso, além de importar grandes quantitativos de $\operatorname{armas}^{8}$, aperfeiçoaram seu sistema repressivo em Angola: "em 1954, o sistema prisional metropolitano de 1936 foi transferido para os territórios ultramarinos. No mesmo ano, a Polícia Internacional e de Defesa do Estado (PIDE) chegou oficialmente em Angola, com os seus quartéis gerais em Luanda (Silva 75,2016 )". Além disso, em 1961 foram instituídos os campos de concentração de Chão Bom (Cabo Verde) e Missombo (Angola), sendo que o campo de São Nicolau, no sul de Angola, já se encontrava em funcionamento desde a década de 1950 (Medina 59 ,2003). Vale dizer que os três campos eram destinados a presos políticos.

Durante doze anos, Luandino viveu entre as prisões e o campo, instituições que, segundo o sociólogo Erving Goffman, podem ser definidas “totais”. De acordo com Goffman, uma instituição total é um lugar onde um grande número de indivíduos vive isolado da sociedade e em regime fechado durante um período de tempo considerável, conduzindo uma existência administrada em todos os detalhes por algum tipo de autoridade (Goffman 1991, p.11). Ao entrar numa instituição total, o indivíduo passa por uma série de mortificações que atingem o seu corpo, assim como a ordem simbólica das coisas. A imagem que o preso tem de si mesmo é abalada. Ele é obrigado a renunciar ao seu aspecto físico (passando, por exemplo, por cortes obrigatórios de cabelo ou barba), às suas posses materiais (entre as quais, a indumentária, que é trocada por roupa padrão fornecida pela instituição) e, em alguns casos, ao próprio nome, que é substituído por um número de identificação. Além disso, o preso é forçado a se submeter a práticas humilhantes, como se despir na frente de muitas pessoas, ser revistado, ou ter que tratar as autoridades com humilhante reverência.

Os processos pelos quais o preso tem que passar, como explica Goffman, "poderiam ser chamados 'triagem' ou 'programação', já que ao se submeter [a eles] o indivíduo permite que o convertam em algo que pode ser introduzido na máquina administrativa da instituição, e que depois pode ser trabalhado docilmente através de operações de rotina (Goffman 26-25,1991)"9. Para criar corpos dóceis e disciplinados, as instituições totais funcionam segundo o princípio do castigo e da recompensa: quanto mais um preso colaborar com as autoridades, tantos mais privilégios ele obterá. A não colaboração, ou pior, a rebelião, são violentamente reprimidas.

Esse sistema opressor, todavia, pode ser-etem sido-desafiado seja por ações individuais ou por ações de massa. Goffman considera tal possibilidade e admite que "às vezes, grupos de presos tem sido fortes o suficiente para organizar greves e breves insurreições [...] mas essas ações comunitárias parecem ser meras exceções e não a regra (Goffman 61-60,1991)”.

8 “[...] em 1959, Angola importou 156 toneladas de armas e munições; em 1960, 953 toneladas; [...] em 1961, estes números baixaram para 424 toneladas e, em 1962, para 145 toneladas. Não era certamente para caçar elefantes, mas sim para resistirem aos africanos, caso eles se revoltassem, que os portugueses abasteceram os seus arsenais (Wheeler et al. 2009, 249-50)".

9 É possível identificar aqui uma conexão com Foucault e a sua ideia de 'corpos dóceis', que seriam o produto das instituições disciplinares. Segundo a definição foucaultiana, através da disciplina, "um corpo dócil pode ser subjugado, usado, transformado e melhorado" (Foucault 1995, p.136). 
Da análise de Goffman, parece que a instituição total é, apesar de tudo, inexpugnável. Ao contrário, a história mostra que há sempre espaço para brechas no sistema institucional ${ }^{10}$. Esse espaço é o espaço da resistência, é o elemento humano que foge à lógica da instituição total.

Práticas e estratégias de resistência são documentadas tanto entre presos políticos quanto entre os chamados presos comuns. No entanto, elas tendem a ter mais êxito no caso dos presos políticos. Como aponta McEvoy, os presos políticos:

[...] estão numa posição de maior poder frente ao sistema prisional com respeito aos presos comuns. Os presos políticos podem chegar a se organizar coletivamente dentro da prisão; o moral dos indivíduos e do grupo tende a ser mais alto; podem ter uma longa história de luta dentro da prisão da qual podem tirar lições e inspiração; é provável que entre eles haja presos com grandes dotes organizativas, militares ou intelectuais; podem ser apoiados por órgãos políticos, advogados cheios de boa vontade e, claramente, movimentos organizados que podem fornecer assistência (McEvoy, 2015, p. 8).

Para os presos políticos, a prisão muitas vezes representa não o fim, mas uma nova etapa da luta, o que é fundamental para encarar a experiência da prisão de forma a não se deixar aniquilar por ela.

$\mathrm{O}$ fato é que $\mathrm{O}$ espectro das práticas de resistência que podem ser adotadas pelos presos é muito amplo. A nível coletivo, alguns exemplos de resistência frente ao sistema prisional incluem organizar greves de fome para pedir melhores condições de vida dentro da prisão; se recusar a fazer trabalho forçado; trabalhar mais devagar e produzir menos; organizar comitês políticos; criar rede de comunicações clandestinas, etc. A nível pessoal, resistir pode significar estudar, praticar algum esporte ou, simplesmente - e na medida do possível- não se deixar abalar pelas mortificações e não se humilhar frente às autoridades prisionais ${ }^{11}$.

10 A visão da instituição total como irremediável aniquiladora do indivíduo pode ser o resultado da definição demasiado abrangente que Goffman tenta elaborar. De fato, para criar uma definição de instituição total, Goffman mistura exemplos de campos de concentração nazistas, prisões comuns, manicômios, orfanatos, ordens monásticas e militares. Embora seja possível reconhecer algumas caraterísticas comuns a essas instituições, também se notam logo grandes diferenças. Claramente, com respeito a uma cadeia ou prisão comum, no caso de um campo de extermínio, as possibilidades de abrir brechas são reduzidas ou nulas, já que a mais ridícula das transgressões pode ser punida com a morte. Mesmo assim, também nos Lager nazistas houve episódios de resistência coletiva (cf. Mahera 2010), além de episódios de resistência individual, como, por exemplo, slowdown e roubos. A esse propósito, é possível ler o conto “Cerio”, de Primo Levi, inserido na coletânea Il sistema periodico (cf. Levi 1975).

11 Um exemplo vem de Robben Island, prisão sul-africana onde ficou a maioria dos presos políticos anti-apartheid. Os presos eram obrigados a chamar os guardas de Baas, patrão, uma palavra em afrikaans que evocava remissão frente ao sistema racista contra os quais os presos tinham lutado. Para não se humilhar e, ao mesmo tempo, não ser punidos pelos carcereiros, os presos passaram a chamar os guardas de Baastard, pronunciando a segunda parte da palavra mais baixinho para não serem ouvidos (cf. Buntman, 2003). 
Os cadernos reunidos em Papéis da Prisão, enquanto objetos materiais, já são um exemplo de resistência em si: durante onze anos, Luandino conseguiu fabricar os cadernos com material de circunstância encontrado na prisão, mantê-los sempre escondidos da polícia e achar alguém que os levasse para fora da prisão. A materialidade dos cadernos testemunha a vontade de continuar a cultivar um espaço íntimo e pessoal, o espaço da escrita, afastado de qualquer tipo de controle ou supervisão.

No seu trabalho sobre as práticas de resistência desenvolvidas pelos presos políticos em Robben Island, a historiadora Fran Buntman distingue entre resistência estratégica e resistência categórica. Esta última, se foca em questões de princípio, sendo portanto um desafio descarado às autoridades da prisão: quem se engaja nessa prática está preparado a não aceitar compromissos apesar de eventuais repercussões violentas. Ao contrário, a resistência estratégica é um projeto de mais longo prazo, que procura criar condições de -pelo menos aparente- tranquilidade, para que os presos façam um uso "vantajoso" da prisão, procurando tirar o máximo proveito das circunstâncias. Pode-se dizer que no primeiro caso, a resistência é um fim em si mesma, enquanto no outro é também um meio para atingir outros resultados (Buntman 128,2003 ).

Um exemplo de resistência categórica pode ser o de um preso que se deixa morrer durante uma greve de fome se as suas demandas não forem atendidas ${ }^{12}$. Outro exemplo, embora menos drástico, é a decisão de Luandino de deixar de receber cartas da sua mulher, para evitar que a censura as lesse e retirasse delas informações que podiam prejudicar a sua família ou outras pessoas. Essa decisão foi comunicada à mulher através de uma carta, que implicitamente era dirigida também aos censores e que, portanto, tinha um tom indiscutivelmente político embora tratasse de um assunto tão íntimo como a correspondência entre um casal obrigado a viver separado. O tom da carta deixa claro que o que está em jogo é uma questão de princípio $^{13}$.

Ao contrário, um exemplo de resistência estratégica é usar o tempo da reclusão para conseguir um diploma acadêmico ou, mais em geral, para estudar. Os Papéis da Prisão testemunham como em todas as prisões pelas quais o Luandino passou, os presos encontraram sempre um meio de organizar aulas. Desde aulas de alfabetização para quem

12 McEvoy define essa prática resistência como sacrifício e explica: "a greve de fome é uma estratégia de resistência usada contra um inimigo aparentemente mais poderoso. Através de um processo de negação, sacrifício e perseverança, o próprio corpo é transformado num lugar simbólico de luta. [...] A força de uma greve de fome deriva da vontade do preso de aguentar, deixando exposta a 'crueldade' de um estado poderoso e procurando apoio entre a comunidade local e internacional (McEvoy 2015, 13)". É conhecido o caso de Bobby Sands, que organizou uma greve de fome contra a decisão do governo britânico de retirar dos presos do IRA o status de presos políticos. A greve não previa marcha atrás, e era organizada de tal maneira que se um dos presos morresse, outros continuariam em greve. Isso levou, em 1981, à morte do próprio Sands e de mais 9 presos. As consequências da greve - o desenvolvimento do braço político do IRA (Sinn Féin) e a pressão internacional sobre o governo de Margaret Thatcher- demostram que a estratégia de resistência teve os seus efeitos positivos, apesar das graves perdas. 13 Para uma melhor compreensão da questão, transcrevo aqui alguns trechos significativos da carta, que é datada 12 de janeiro de 1967: "Não creio que te surpreenda muito o meu telegrama pedindo-te que me não escrevas mais. Mas é possível que te custe bastante «obedecer» a esse meu pedido sabendo como bem sabes, o que a tua correspondência vale para mim. Mas como parece que ela tem outro valor para outrem, eu não gosto de coisas partilhadas deste modo. [...] Custará muito, doerá muito, mas dói muito mais dar satisfação aos nossos inimigos. E mesmo sem notícias e com visitas problemáticas a vida andará. Não é pela vontade dos homens que ela tem andado até onde andou já. Quero eu dizer: de certos homens. [...] Não é possível viver em tempos destes sem estes casos. A honestidade é paga pelo preço que antes se exigia aos grandes criminosos. Sinal evidente que «um anjo virá com uma trombeta» como disse S. João no seu apocalipse. Se não virmos esse dia, o Xexe o verá. E a nós restar-nos-á a ínfima mas legítima alegria humana de mesmo depois de convertidos em vermes que a terra albergará, irmos roendo as terras sob os pés dos tiranos de todo o mundo, que aluirão (Vieira 2015, 774-78)”. 
entrava na prisão sem saber ler nem escrever, até sessões de debates sobre literatura, os presos tentaram usar o tempo da reclusão para aprimorar sua educação e formação. Não por acaso, ao falar retrospectivamente da sua experiência no cárcere, muitos presos afirmam que estar preso foi como frequentar uma universidade ${ }^{14}$. Essa definição tem muitas vezes conotações políticas, pois foi no cárcere que muitos desenvolveram ou radicalizaram sua consciência política, sobretudo através do contato com militantes mais politizados.

A nível individual, Luandino frequentou um curso de sociologia por correspondência da Universidade da Califórnia e se matriculou no curso de Guitarra Clássica da École Universelle de Paris (cf. Vieira 1029 ,2015). Além disso, o escritor se dedicou ao estudo de línguas, como por exemplo o russo e, mais importante, o quimbundo, língua oriunda de Angola da qual Luandino tinha um conhecimento rudimentar antes de entrar na prisão. O interesse pelo quimbundo enquanto patrimônio cultural de Angola é evidente no projeto do Cancioneiro Popular Angolano, projeto ao qual o Luandino se dedicou com constância ao longo dos anos de reclusão, construindo um acervo composto por dezenas de canções em quimbundo. A intenção que motivava a compilação do cancioneiro é claramente difundir a cultura angolana; por isso o autor enviava as canções recolhidas para seus companheiros fora da prisão, para que eles pudessem «aproveitá-las para alguma coisa» porque «quietas não dão filhos (Vieira 433,2015 )». Entretanto, a aprendizagem do quimbundo foi útil também na perspectiva do escritor: Luandino incorpora essa língua à sua escrita e a transforma num elemento estético que remete à cultura tradicional angolana e, ao mesmo tempo, a um modo novo, autoral, de entender essa cultura.

É preciso dizer que a resistência que os presos opõem ao sistema carcerário não tem efeitos diretos só sobre o que acontece dentro da prisão, mas também no mundo fora. Se uma das caraterísticas que Goffman identifica nas instituições totais é que criam uma tensão entre o dentro e o fora, e uma tensão que é usada para manipular o preso, através da resistência é possível ultrapassar essa dualidade. A transmissão de informações e material para fora da prisão é uma das maneiras para ultrapassar essa tensão e é uma das caraterísticas importantes dos primeiros onze cadernos dos Papéis, escritos em Luanda. É através dessa prática que a participação ativa de Luandino no movimento de libertação não ficou de todo interrompida por causa da prisão.

Entre as informações que Luandino passava para fora, havia os nomes de quem entrava ou saía da prisão, os nomes de quem colaborava com a polícia, relatos sobre sessões de tortura e espancamento. Da prisão também saíram os contos de Luuanda, coletânea que, em 1965, ganhou o primeiro prêmio da Sociedade Portuguesa de Escritores, o que levou à extinção desta Sociedade pela PIDE e à detenção dos membros do júri que tinha atribuído o prêmio.

Uma prática paralela à transmissão de informações é a criação dos “arquivos

14 Isso não se limita à experiência angolana, mas é uma condição comum para muitos presos políticos. Pense-se, por exemplo, na prisão de Robben Island, que ficou conhecida na história sul-africana como 'the university' (cf. Buntman 2003). 
implacáveis" ${ }^{15}$. Luandino recolhia, catalogava e numerava todo o material que podia ter algum interesse para uma futura história de Angola e da cultura angolana. Nos arquivos, entre outras coisas, encontram-se alguns bilhetes que Luandino recebia de outros presos, recortes de jornais sobre o próprio processo ou o desenho do mapa da primeira cadeia onde esteve preso ${ }^{16}$. Para quem foi preso lutando, a prisão também é parte da história que merece ser guardada no arquivo.

IMAGEM 1

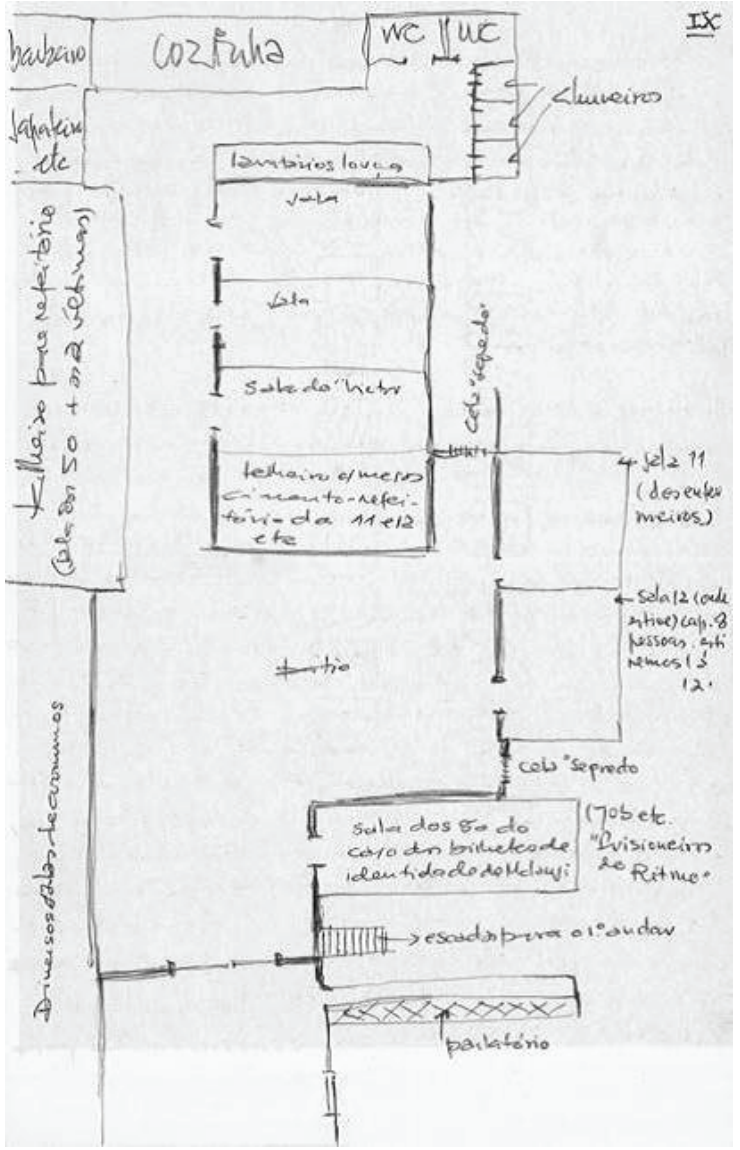

Página do caderno correspondente ao dia 1963/02/1.

Desenho das plantas da Casa de Reclusão (Vieira 127 ,2015)

$\mathrm{Na}$ óptica do escritor, o arquivo é fonte de inspiração no sentido de fornecer temas e personagens para narrativas futuras. O projeto literário de Luandino é anterior à prisão, mas é inegável que seu desenvolvimento foi profundamente condicionado pela experiência da reclusão. Na leitura dos Papéis, o leitor se depara muitas vezes com referências a projetos

15 A expressão era difundida no meio intelectual anticolonial angolano, como confirma esse trecho de autoria de Carlos Ervedosa, amigo de Luandino e autor de um famoso Roteiro da literatura angolana: "Começamos a guardar as cartas que nos chegavam do Tarrafal. Aliás, andávamos todos, há já alguns anos, a guardar desenhos, poemas, contos e outros escritos, uns dos outros, impublicáveis nesse tempo, formando os nossos 'arquivos implacáveis', como então lhes chamávamos (Laban 1980, 94)".

16 Luandino Vieira foi preso pela primeira vez entre julho e agosto de 1959, tendo ficado no Pavilhão Prisional da PIDE e na Casa de Reclusão Militar de Luanda (Medina 2003, 77-78). 
futuros, ou com o escritor que justifica a anotação de um episódio nos cadernos em vista de um possível aproveitamento no futuro ${ }^{17}$.

Os cadernos revelam que, para fugir ao controle disciplinar da prisão, Luandino se auto-impôs uma contra-disciplina. Parte dela consistia em escrever, e escrever o mais possível, ao ponto que há nos cadernos páginas nas quais Luandino se repreende por não ter conseguido escrever ou terminar o trabalho que tinha se proposto a fazer ${ }^{18}$.

A dedicação à escrita é evidente também em todos os fragmentos dos Papéis nos quais Luandino discorre sobre o próprio processo criativo e sobre o estilo literário que estava conscientemente construindo. Segundo as palavras do próprio autor (cf. Vieira 1072,2015), duas decisões foram fundamentais para ele não se deixar aniquilar pela prisão: a decisão de escrever e a de tentar manter um relacionamento muito íntimo com a mulher, apesar da impossibilidade do contato físico. Os cadernos luandenses conjugam as duas coisas. Durante as visitas, Luandino entregava os cadernos à mulher para que ela os guardasse em lugar seguro. Neles, estabeleceu um verdadeiro diálogo com a mulher, cujo papel era tríplice: primeira leitora e crítica, companheira no amor e camarada na luta. Ao tom romântico e familiar de alguns fragmentos, alterna-se um tom mais pragmático, militante.

IMAGEM 2

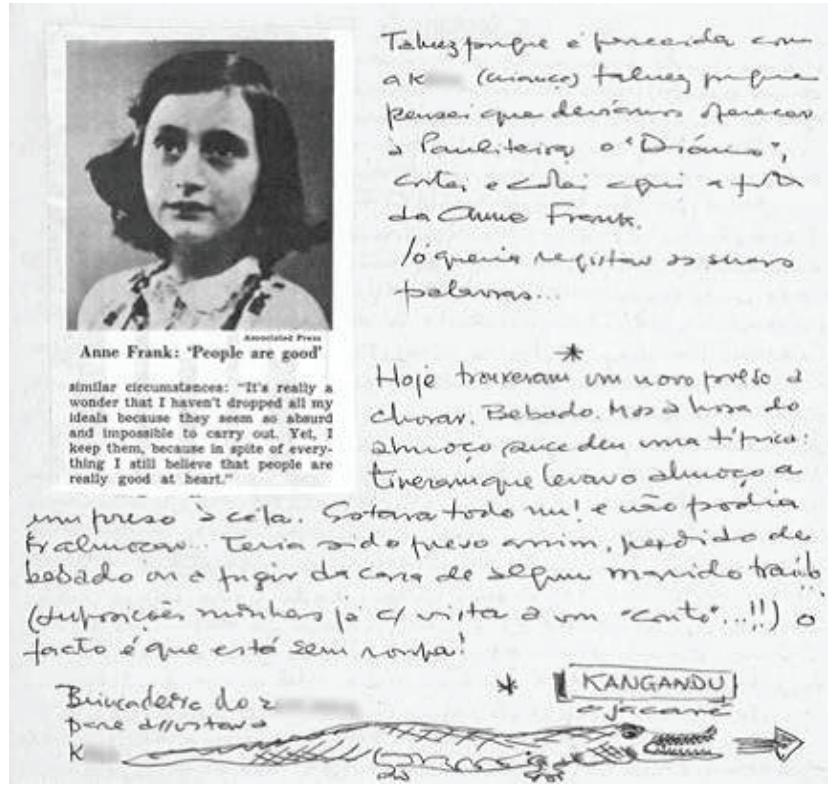

Página do caderno correspondente ao dia 1963/06/17.

No fundo da página Luandino desenha um jacaré como "brincadeira do Z. para assustar a

\begin{abstract}
17 Anotações desse tipo são recorrentes nos cadernos e seria impossível dar conta aqui de todas. Como exemplo, transcrevo uma delas, datada 28/2/1963: “ [...] Para não esquecer: além do que o A.J. me contou do Amaral Ferrovelho, um dia relembrar tudo qto. sei do Crista e do Quintino (tipos do lúmpen-proletariado branco, que vivem de expedientes no musseque) e da amásia do Quintino, a prostituta Camélia (que belo nome). Quintino também já foi preso pela pide e levou pancada! Um velhote arruinado! Penso que com os carácteres destes tipos todos, mais ainda os do Quinhentas, do Rebocho, e do Salambiô, posso um dia fazer uma novela ou coisa parecida (Vieira 2015, 155)".

18 Veja-se por exemplo a entrada dos cadernos do dia 26/06/1963: "Acabo de trabalhar mais um bocado na novela curta (ou conto longo...) «Muxiluanda». 45m[inutos] de trabalho esgotaram-me. Estive a escrever sempre com um olho crítico em cima de mim e isso fazia-me duvidar de tudo qto. estava a escrever. Saiu uma porcaria. Terei que ter muito trabalho para fazer daquilo tudo um trabalho decente (Vieira 2015, 338)".
\end{abstract}


IMAGEM 3

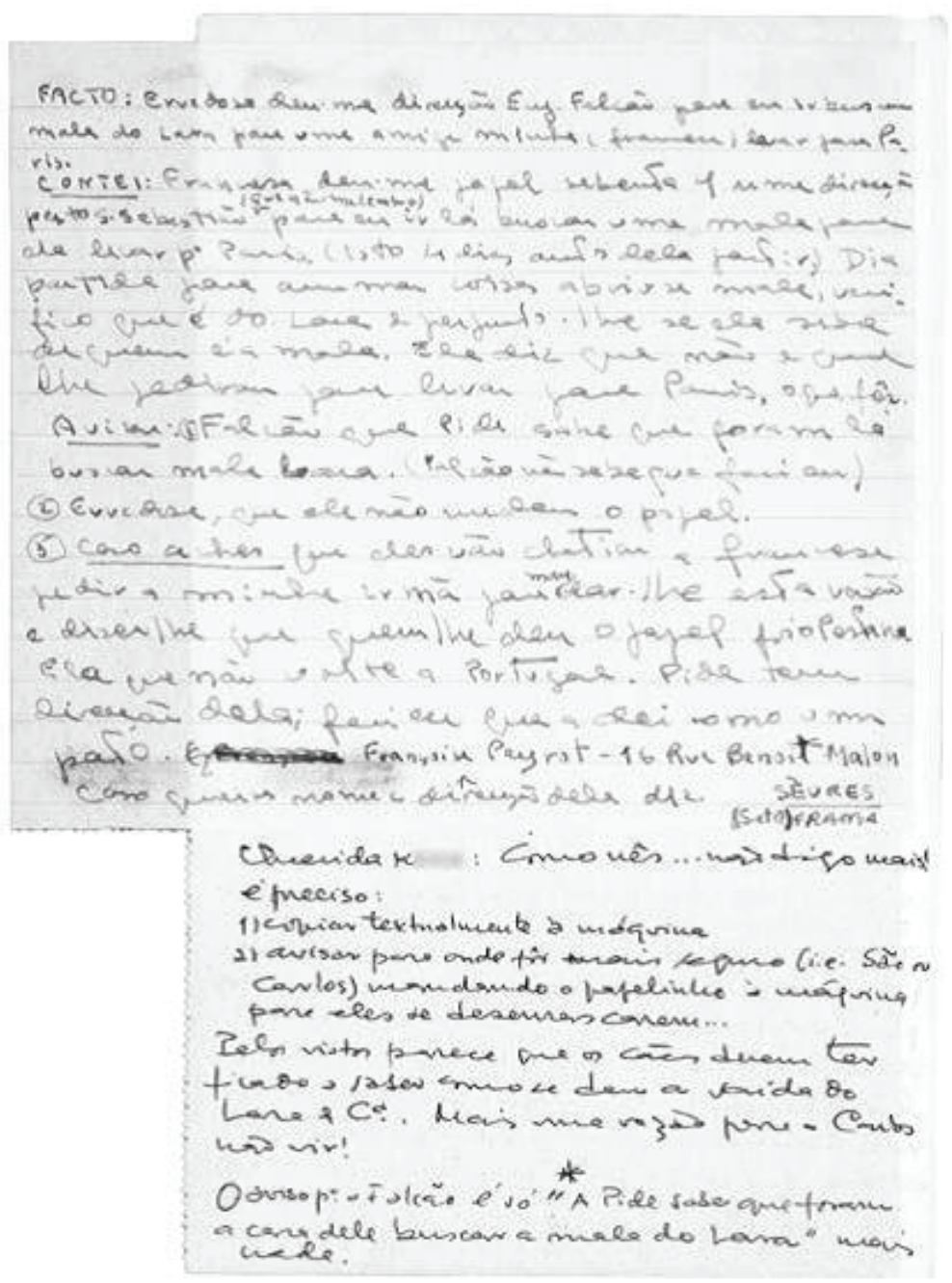

Página do caderno correspondente ao dia 1963/05/22.

A um bilhete entregado por um preso a Luandino com as informações sobre um interrogatório com a PIDE, o escritor junta um bilhete à K. com as instruções sobre como agir:

"Querida K. Como vês... não digo mais! É preciso:1) copiar textualmente à máquina 2) avisar para onde for mais seguro [...]" (Vieira 306,2015$)$

Na segunda parte dos Papéis, a que recolhe os cadernos escritos no Tarrafal, isso se perde. Ao encarceramento junta-se o exílio, o afastamento da terra, da luta e dos afetos. O diálogo com a K./L. ${ }^{19}$ fica interrompido e a escrita se torna um monólogo, mais autoreflexivo, muito mais fragmentário também. Observando bem, ainda há diálogo, mas agora é entre José Vieira Mateus da Graça, nome oficial do escritor, e Luandino, seu alter ego literário: o Zé se dirige ao Luandino usando a segunda pessoa e, conversando com a sua

19 As duas iniciais K. e L. são usadas nos Papéis para identificar Linda, a esposa de Luandino Vieira. 
mulher, Zé fala do Luandino usando a terceira pessoa, "como se fosse outro (Vieira ,2015 892)". Simplificando algo que é muito complexo e cujos contornos não são tão bem definidos como aqui os apresento ${ }^{20}$, pode-se dizer que Zé é o nome próprio, o nome dos afetos, aquele usado pela mulher e pelos amigos, enquanto Luandino é o nome que representa o empenho político e literário, é o nome do escritor.

Os anos do Tarrafal são aqueles da mais intensa atividade literária para Luandino ${ }^{21}$. Por isso, enquanto a escrita dos cadernos fica mais fragmentária, a escrita literária é torrencial ${ }^{22}$. Se desde o começo da sua experiência na prisão ele tinha a obsessão de acumular anedotas e esboços sobre tipos humanos encontrados na cadeia, os anos do Tarrafal são os da reelaboração e aproveitamento desse material para a literatura. A escrita não é só passatempo e não tem só uma função terapêutica: ela é também uma forma de resistência, desta vez não só no sentido de ser um meio para se subtrair ao entorno da prisão e ao seu sistema de mortificações e humilhações. A resistência agora se constitui como tema das narrativas - sempre críticas da ordem constituída - e como forma imanente da escrita (cf. Bosi 2002).

Gostaria de concluir voltando à ideia que a resistência não tem efeitos só sobre o mundo dentro da prisão, mas também no de fora. A literatura produzida por Luandino Vieira no cárcere também é um exemplo de resistência neste sentido, já que os efeitos a posteriori que essa literatura teve na cultura angolana são enormes, na medida em que ela contribuiu à criação de uma identidade nacional que reforçou o projeto político da independência e o discurso do movimento ao qual Luandino estava ligado, o MPLA ${ }^{23}$. O movimento se mantém no poder desde 1975 e, com o tempo, parece divergir cada vez mais do ideal que levou à sua formação em meados do século passado.

\section{REFERENCIAS}

Bosi, Alfredo. 2002. "Narrativa E Resistência." Em Literatura E Resistência, 118-35. São Paulo: Companhia das Letras.

Buntman, Fran Lisa. 2003. Robben Island and Prisoner Resistance to Apartheid. Cambridge: Cambridge University Press.

20 Um indício da complexidade por detrás dessa questão são as cartas assinadas como Zéluandino, num gesto que parece assumir e reivindicar ambas as personalidades. Tome-se como exemplo a já citada carta de 12/01/1967.

21 Essa é a tendência geral dos anos do Tarrafal que, porém, não se apresenta homogênea. Por exemplo, no período de aclimatação ao campo, entre 1964 e 1967, Luandino escreveu muito pouco e se dedicou mais a outras atividades (Vieira 2015, 1029).

22 Os Papéis já foram definidos como um volume paraliterário (cf. Calafate Ribeiro \& Vecchi 2015), logo, é interessante lê-los em relação às obras de ficção que Luandino Vieira escreveu na prisão. Podem ser pensados como elementos contrapontísticos, porque tomadas singularmente, tanto as obras literárias como os Papéis, são vozes autônomas, porém seu entrelaçamento cria uma unidade, uma harmonia mais complexa e mais completa. Partindo dessa perspectiva, é interessante ver como os temas e as anedotas passam dos diários às obras literárias e vice-versa, e quais são os pontos de contato ou de divergência entre eles.

23 Como explica a historiadora angolana Maria da Conceição Neto: “[...] no nosso país se recorre ainda, passadas várias décadas, ao inegável capital político derivado da participação ativa na luta de libertação nacional para estabelecer legitimidades, direitos, reconhecimento social ou, então, para desacreditar eventuais adversários (Neto 2003, 15)”. 
Goffman, Erving. 1991. Asylums: Essays on the Social Situation of Mental Patients and Other Inmates. Harmondsworth, New York: Penguin (1 $1^{\text {a }}$ edição 1961).

Laban, Michel (org.). 1980. Luandino - José Luandino Vieira E a Sua Obra: Estudos, Testemunhos, Entrevistas. Lisboa: Edições 70.

Levi, Primo. 1975. Il Sistema Periodico. Turim: Einaudi.

Mahera, Thomas V. 2010. "Threat, Resistance, and Collective Action: The Cases of Sobibór, Treblinka, and Auschwitz." American Sociological Review 75 (2): 252-72.

Marcum, John. 1969. The Angolan Revolution. Volume I. The Anatomy of an Explosion (1950-1962). Vol. I. Massachusetts Institute of Technology: The M.I.T. Press.

McEvoy, Kieran. 2015. "Political Prisoners, Resistance and the Law in Northern Ireland.” Belfast: Queen's University.

Medina, Maria do Carmo. 2003. Angola: Processos Políticos Da Luta Pela Independência. Luanda: Faculdade de Direito da Universidade Agostinho Neto.

Neto, Maria da Conceição, 1997. "Ideologias, Contradições e Mistificações da Colonização de Angola no Século XX”. Lusotopie, pp.327-359.

Neto, Maria da Conceição. 2003. "Breve Introdução Histórica." Em Angola: Processos Políticos Da Luta de Independência, 15-30. Luanda: Faculdade de Direito da Universidade Agostinho Neto.

Ribeiro, Margarida Calafate e Roberto Vecchi. 2015. "Papéis Críticos Avulsos." Em Papéis Da Prisão. Apontamentos, Diário, Correspondência (1962-1971), 13-31. Lisboa: Caminho.

Silva, Mónica V. 2016. “Luanda Through Its Prisons: Luandino Vieira’s Papéis Da Prisão.” Journal of Lusophone Studies 1 (1): 73-87.

Vieira, Luandino José. 2015. Papéis Da Prisão. Apontamentos, Diário, Correspondência (1962-1971). Organização de Margarida Calafate Ribeiro, Roberto Vecchi, e Mónica V. Silva. Lisboa: Caminho.

Wheeler, Douglas L, René Pélissier, Pedro Gaspar Serras Pereira, e Paula Almeida. 2009. História de Angola. Lisboa: Tinta-da-china. 